\title{
Documentos dos EUA referentes às ditaduras do Cone Sul:
}

\section{desafios metodológicos}

Mariana Joffily ${ }^{1}$

Resumo: Nas últimas décadas, diversos documentos provenientes de agências governamentais estadunidenses têm sido disponibilizados para consulta pública pelo National Security Archive, organização de pesquisa independente, em alguns casos sob demanda de países como a Argentina, o Chile ou o Brasil, com vistas a embasar processos judiciários ou trabalhos de comissões da verdade, relacionados a violações dos direitos humanos pelas ditaduras militares nesses países. Este artigo traz reflexões sobre alguns desafios metodológicos colocados por esses acervos e fontes relativos à integração das múltiplas dimensões temporais, ao papel dos indivíduos e das estruturas, à articulação das esferas nacionais e transnacionais e ao viés aportado por uma documentação produzida por agências governamentais estadunidenses.

Palavras-chave: Ditaduras Militares, Relações Internacionais, Política Externa.

\section{US files regarding Southern Cone dictatorships:}

\section{methodological challenges}

\begin{abstract}
In the last three decades, many documents coming from US governmental agencies have been made available to public consultation by the National Security Archive, an independent research organization. Some in response to the demand of countries such as Argentina, Chile or Brazil, in order to substantiate lawsuits or the work of truth commissions, related to human rights violations by the military dictatorships in these countries. This paper reflects on some methodological challenges associated to these document collections and sources, such as the

\footnotetext{
${ }^{1}$ Doutora em História pela Universidade de São Paulo (USP), Professora do Departamento e do Programa de Pós Graduação em História da Universidade do Estado de Santa Catarina (UDESC), Brasil. Esse artigo é fruto de pesquisa de pós-doutorado na Universidade de Brown, EUA, (2015-2016) e contou com financiamento da CAPES/Fulbright. Atualmente desenvolve, em conjunto com Maud Chirio, a pesquisa intitulada "A repressão em carne e osso: Formação, treinamento e trajetória profissional de agentes repressivos da ditadura militar brasileira (1961-1988)", financiada pelo CNPq. E-mail: mariana.joffily@gmail.com
}

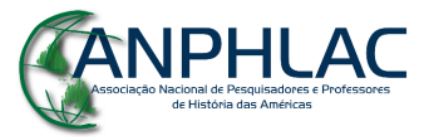

Revista Eletrônica da ANPHLAC, ISSN 1679-1061, №. 25, p. 275-302, Jul./Dez., 2018.

http://revista.anphlac.org.br 
integrations of the multiple temporal dimensions, the role played by structures and individuals, the articulation between national and transnational levels and the biases of a documentation produced by US governmental agencies.

Key words: Military Dictatorships, International Relations, Foreign Policy.

Artigo recebido em: 19/12/2017

Artigo aprovado em: 09/05/2018

Desde a passagem para a democracia dos países do Cone Sul, na década de 1980, os acervos sobre as ditaduras militares vêm se ampliando, o acesso a eles sendo franqueado por diversas agências governamentais ou entidades de defesa dos direitos humanos e ferramentas de buscas mais sofisticadas têm facilitado seu manejo por parte de pesquisadores. O National Security Archive (NSA) é uma das instituições que contribui para o recolhimento e divulgação de documentos sobre tal período. A despeito de seu nome oficial, o arquivo é um instituto independente, sem fins lucrativos, criado por jornalistas, historiadores e ativistas em 1985, durante a administração anticomunista e neoliberal de Ronald Reagan (1981-1989). (CARLSON, 2008, p. C4) Ao longo de mais de três décadas, o NSA reuniu, organizou e disponibilizou para pesquisa diversos conjuntos documentais relacionados a áreas sensíveis da política internacional estadunidense. No conjunto dedicado à América Latina, recobriu temas como a política externa estadunidense, guerra contra as drogas, atos de terrorismo internacional e casos de violações de direitos humanos.

Os conjuntos documentais aqui analisados derivam de três projetos coordenados pelo NSA: "Chile e os EUA: política estadunidense relativa a democracia, ditadura e direitos humanos, 1970-1990”, “Argentina, 1975-1980: a elaboração da política de direitos humanos dos EUA" ${ }^{2}$ e um sobre a ditadura militar brasileira, ainda em tratamento, que reúne a documentação enviada pelo governo

\footnotetext{
${ }^{2}$ No original, respectivamente: Chile and the United States: U.S. Policy toward Democracy, Dictatorship, and Human Rights, 1970-1990 e Argentina, 1975-1980: The Making of U.S. Human Rights Policy.
}

\section{CANPHLAC}

Revista Eletrônica da ANPHLAC, ISSN 1679-1061, №. 25, p. 275-302, Jul./Dez., 2018.

http://revista.anphlac.org.br 
Barack Obama à Comissão Nacional da Verdade $(\mathrm{CNV}) .{ }^{3}$ A singularidade dessa documentação reside em algumas características dificilmente encontradas em fontes nacionais que tratam da violência do Estado contra os oponentes políticos. Em primeiro lugar, trazem um olhar externo às políticas dos governos do Cone Sul, do ponto de vista da potência da qual emanava parte significativa do modelo, da doutrina e da mentalidade que moviam os governos militares e seus apoiadores civis. Em segundo, revelam o grau de conhecimento e implicação dos Estados Unidos na violência perpetrada por esses governos contra seus opositores. Em terceiro, em alguns casos revelam bastidores de tomadas de decisão ou perfis de atores-chave das ditaduras da região. Por fim, fornecem valiosas pistas sobre os processos de tomada de decisão da política externa dos Estados Unidos em relação a seus aliados.

Neste artigo, além de descrever em que contextos essas documentações foram recolhidas, pretendo discutir sua natureza, seu escopo e seus limites. Proponho, ademais, levantar alguns desafios metodológicos para o trabalho com tais fontes. Como trabalhar a média e a longa durações tendo por referência uma documentação que trata do cotidiano do processo decisório das agências governamentais, frente às relações internacionais e crises políticas? Que nível de equilíbrio seria factível encontrar entre o peso dos personagens que nesses documentos aparecem por vezes como todo-poderosos e os processos mais gerais e estruturais do período? É possível pensar uma perspectiva transnacional partindo de fontes cuja organização arquivística pauta-se pelos Estados Nacionais? Até que ponto o uso de uma documentação proveniente das agências governamentais estadunidenses nos conduz a supervalorizar o papel dos Estados Unidos na deflagração de golpes e na sustentação de regimes autoritários no Cone Sul?

\footnotetext{
${ }^{3}$ A pesquisa no acervo do NSA apenas pode ser realizada na própria sede do arquivo, na biblioteca Gelman, na Universidade de George Washington em Washington DC e na Biblioteca do Congresso, ambas nos EUA. Contudo, vários documentos são disponibilizados pela internet nos Electronic Briefing Books, inclusive sobre o Brasil, disponíveis em: http://nsarchive.gwu.edu/NSAEBB/. No Brasil pode-se acessar parte da base a partir do Laboratório de Estudos da Contemporaneidade da Universidade do Estado de Santa Catarina (sob consulta prévia). Quanto à documentação enviada pelos Estados Unidos à Comissão Nacional da Verdade, está acessível em formato digital no Arquivo Nacional do Rio de Janeiro: http://www.an.gov.br/sian/inicial.asp (em "Comissão Nacional da Verdade" e "Reconhecimento de acervos"). Muitos documentos sobre a ditadura militar brasileira também podem ser consultados on line pelo projeto Opening the Archives em http://library.brown.edu/openingthearchives/, uma iniciativa da Universidade de Brown, conduzida pelo brasilianista James Green com apoio da Universidade Estadual de Maringá.
}

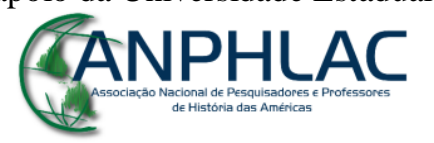

Revista Eletrônica da ANPHLAC, ISSN 1679-1061, №. 25, p. 275-302, Jul./Dez., 2018.

http://revista.anphlac.org.br 
Se esses desafios não são específicos a esses acervos, problematizar como se colocam para esse corpus documental específico, considerando as particularidades do período histórico que o produziu, contribui a refletir sobre os componentes que devem ser avaliados no momento de compor a complexa trama das relações entre os Estados Unidos e as ditaduras militares no Brasil, no Chile e na Argentina no que diz respeito à repressão política.

\section{Os projetos Chile, Argentina e Brasil: natureza e escopo das documentações}

\section{Chile $^{4}$}

O projeto que levou a administração de Bill Clinton a colocar à disposição do público milhares de documentos governamentais estadunidenses até então secretos sobre a ditadura chilena foi uma das consequências da prisão de Augusto Pinochet em Londres, em outubro de 1998. Apesar da pressão de familiares de vítimas, de congressistas estadunidenses e de ONGs ligadas ao direito à informação e à defesa dos direitos humanos, a administração Clinton resistiu a desenvolver qualquer política que auxiliasse a inédita iniciativa da Espanha de utilizar o direito internacional para julgar o ditador chileno. ${ }^{5}$ Porém, cedendo ao aumento significativo das pressões suscitadas pelo evento internacional, o governo estadunidense acabou por anunciar em fevereiro de 1999 uma revisão da documentação relativa ao Chile, em nome da reconciliação da sociedade chilena e do estabelecimento da verdade. O projeto contou com a participação do NSA, do Conselho de Segurança Nacional, do Pentágono, do Departamento de Justiça e, de forma extremamente relutante, da Agência Central de Inteligência (CIA). Ao todo, foram 24 mil documentos liberados ao público, ${ }^{6}$ que, segundo o analista do NSA, Peter Kornbluh,

oferecem uma oportunidade de ser uma mosca pousada na parede enquanto presidentes, conselheiros de segurança nacional, diretores da CIA e secretários de Estado debatiam

\footnotetext{
${ }^{4}$ Salvo outras indicações, as informações dessa seção foram extraídas de KORNBLUH, NSA.

${ }^{5}$ Três meses antes, em julho de 1998, os Estados Unidos votaram contra a criação de um Tribunal Penal Internacional Permanente, o TPI. Temiam que seus oficiais das forças armadas ou outras autoridades fossem julgados por crimes de guerra. (Agradeço essa informação transmitida pelo/a parecerista do artigo.)

${ }^{6}$ Consultáveis no site www.state.gov.
}

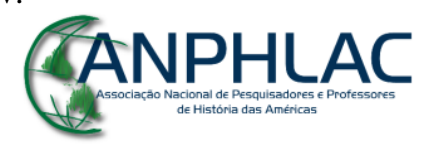

Revista Eletrônica da ANPHLAC, ISSN 1679-1061, №. 25, p. 275-302, Jul./Dez., 2018.

http://revista.anphlac.org.br 
sobre decisões cruciais e formulavam ordens que mudariam os destinos da nação. Permitem também ao leitor observar o processo de como essas ordens foram implementadas no Chile dia-a-dia, minuto por minuto ${ }^{7}$ (KORNBLUH, 2013)

A coleção de 2.842 documentos ${ }^{8}$ que o NSA contém sobre o Chile é consideravelmente mais modesta do que o acervo liberado para consulta no site do Departamento de Estado, mas ao mesmo tempo integra documentos retirados de outras fontes. A coleção reúne seleções - em torno de casos específicos e de acontecimentos-chave da política dos Estados Unidos em relação ao Chile - da base disponibilizada pelo Departamento de Estado, documentos censurados obtidos a partir do Freedom of Information Act (FOIA), ${ }^{9}$ outros coletados de investigações judiciais decorrentes de processos movidos por familiares de mortos e desaparecidos contra perpetradores, e do processo da procuradoria estadunidense contra o diretor da CIA Richard Helms, por ter mentido em audiências do Congresso estadunidense. ${ }^{10}$ Outros, ainda, foram recolhidos nas bibliotecas presidenciais, em arquivos de outros governos, no Arquivo do Terror encontrado no Paraguai, ou doados por pesquisadores.

Esses documentos podem ser classificados em três categorias. A primeira reúne o material produzidos pelas esferas de decisão política: o Departamento de Estado, o Conselho de Segurança Nacional, o Departamento de Justiça, o Departamento de Defesa e, em alguns casos, a CIA. Correspondem a aproximadamente $30 \%$ da documentação. A segunda contém documentos gerados pelos setores intermediários: a embaixada e os consulados estadunidenses, a CIA $^{11}$ em particular o braço da CIA de Santiago. Ou seja, fontes criadas para informar o alto

\footnotetext{
${ }^{7}$ (Tradução da autora.) No original: "offer an opportunity to be a fly on the wall as presidents, national security advisers, CIA directors, and secretaries of states debated crucial decisions and issued nationchanging orders. They also allow the reader to observe the minute-by-minute, day-by-day process of how those orders were implemented in Chile."

${ }^{8}$ Esse é o número original de documentos da base. Novos documentos desclassificados foram sendo incorporados ao acervo.

${ }^{9} \mathrm{O}$ ato foi estabelecido em 1966, mas apenas após o escândalo do Watergate transformou-se em um instrumento utilizável pela população civil para demandar o fim do sigilo sobre determinados documentos.

${ }^{10}$ Em 1977 o então ex-diretor da CIA foi condenado por ter mentido ao Senado sobre as operações secretas conduzidas pela agência no Chile. Helms foi testemunha-chave diante do Comitê conduzido pelo Senador Frank Church em 1975 a respeito de abusos cometidos pela CIA, FBI e Agência Nacional de Segurança em atividades clandestinas de inteligência, incluindo perseguição de ativistas políticos nos EUA e operações que tinham por objetivo o assassinato de líderes políticos de outros países.

${ }^{11}$ É difícil situar a CIA, visto que suas altas esferas participam dos processos decisórios, mas grande parte do material gerado pela agência e liberado para consulta consiste em informes e relatórios.
}

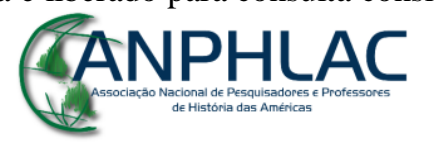

Revista Eletrônica da ANPHLAC, ISSN 1679-1061, №. 25, p. 275-302, Jul./Dez., 2018.

http://revista.anphlac.org.br 
escalão sobre os acontecimentos ocorridos no Chile e relatar a aplicação da política externa dos Estados Unidos no país. Somados, constituem aproximadamente 50\% da documentação. A terceira congrega documentos de origens diversas: agências governamentais chilenas, governos estrangeiros, Arquivo do Terror, arquivos nacionais britânicos e Justiça chilena (investigações sobre Pinochet), somando aproximadamente $20 \%$ da documentação. ${ }^{12}$

Do ponto de vista do recorte temporal, a documentação cobre o período que vai das tentativas por parte dos Estados Unidos de impedir a posse do presidente chileno democraticamente eleito, Salvador Allende, em 1970, até o fim da ditadura militar, em 1990, contendo ainda registros relacionados à transição para a democracia, à prisão de Pinochet e às investigações da Justiça chilena sobre o ditador. 58\% da documentação corresponde às administrações de Richard Nixon (1969-1974) e Gerald Ford (1974-1977), ${ }^{13}$ em seguida, 25\% à de Jimmy Carter (1977-1981), 11\% à de Ronald Reagan (1981-1989) e os demais 6\% são posteriores a 1990.

\section{Argentina $^{14}$}

A coleção sobre a Argentina contém mais de 2.429 documentos ${ }^{15}$ e também foi originada, em parte, de demandas relativas a casos judiciais movidos contra os responsáveis pela repressão política no período ditatorial e de requisições de grupos de familiares de desaparecidos e de defesa dos direitos humanos. Atendendo a pressões que se faziam sentir desde o final dos anos 1990, a administração de Bill Clinton iniciou um processo de desclassificação que foi levado a termo durante o governo de George W. Bush. Em agosto de 2002, o Departamento de Estado disponibilizou 4.700 documentos - um quinto da quantidade de documentos liberados sobre o Chile.

Diferentemente do que ocorreu com o projeto de desclassificação relativo ao Chile, a documentação referente à Argentina levada a público limitou-se, em grande medida, à esfera da embaixada em Buenos Aires e a eventos ocorridos no país,

\footnotetext{
${ }^{12}$ Cálculos aproximados.

${ }^{13}$ Aqui as duas administrações são tomadas em conjunto pelo fato de Gerald Ford ter assumido a presidência quando da renúncia de Richard Nixon, sem ter alterado significativamente a condução da política externa e mantendo os principais protagonistas da administração anterior.

${ }^{14}$ Salvo outras indicações, as informações dessa seção foram extraídas de OSÓRIO, NSA.

${ }^{15}$ Ver nota de rodapé número 8.
}

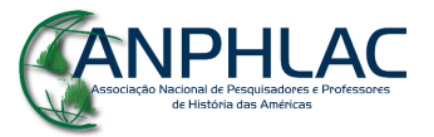

Revista Eletrônica da ANPHLAC, ISSN 1679-1061, №. 25, p. 275-302, Jul./Dez., 2018.

http://revista.anphlac.org.br 
contendo relativamente pouco material sobre o processo de tomada de decisão da política externa estadunidense. Entre as agências, apenas o Departamento de Estado colaborou com o projeto, ao passo que o FBI, a CIA e o Departamento de Defesa recusaram-se a participar do esforço de transparência. Carlos Osório, analista do NSA, comenta que o material liberado não revela a fundo o envolvimento dos Estados Unidos com a ditadura militar argentina. A discrepância entre a quantidade e a qualidade da documentação disponibilizada sobre o Chile e a Argentina talvez possa ser explicada pelo fato de que o profundo envolvimento dos Estados Unidos com a ditadura chilena já era de conhecimento público - embora, claro, não em seus detalhes e em toda sua extensão - e foi alvo de investigações do Congresso estadunidense nos anos 1970. Assim, as agências de inteligência cederam os anéis para não perder os dedos. O caso da Argentina, cuja ditadura desenrolou-se em grande parte durante as administrações de Jimmy Carter e de Ronald Reagan, teve muito menos projeção sobre a opinião pública estadunidense. Além disso, os episódios que ficaram mais conhecidos na relação entre os Estados Unidos com a ditadura argentina foram as pressões no sentido do respeito aos direitos humanos, bandeira da política externa do presidente Carter. No campo da especulação, é possível que os documentos reservados sejam capazes de revelar outros aspectos menos nobres da política externa estadunidense relativa aos militares argentinos.

A coleção sobre a ditadura argentina também não se limita ao material liberado pelo Departamento de Estado. Empregando a metodologia de definição de eventos-chave ${ }^{16}$ - encontros bilaterais, operações de segurança, operações repressivas, massacres e desaparecimento de vítimas, visitas oficiais de governo, entre outros, - e de personagens considerados centrais - seja para a formulação de políticas, seja para sua execução ou entre as vítimas - foram identificados nos diversos acervos documentos relevantes para a caracterização do período. Aqui também o foco está colocado sobre a violação aos direitos humanos bem como as relações entre os Estados Unidos e a ditadura argentina. A coleção abrange centenas de documentos obtidos a partir do FOIA, registros diplomáticos e da CIA garimpados no Arquivo Nacional dos EUA (National Archives and Record Administration), papéis

\footnotetext{
${ }^{16}$ Tratam-se de casos paradigmáticos que ajudam a compreender o período e as questões em causa, além de frequentemente servirem de eixo a interpretações mais gerais sobre o tema. (Trachtenberg, 2006, p. 145)
}

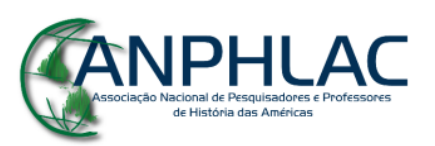

Revista Eletrônica da ANPHLAC, ISSN 1679-1061, №. 25, p. 275-302, Jul./Dez., 2018.

http://revista.anphlac.org.br 
encontrados em bibliotecas presidenciais, material oriundo do Arquivo do Terror do Paraguai, documentos doados por pesquisadores e atores políticos do período e, por fim, material oriundo da Justiça argentina nos processos contra perpetradores de violações aos direitos humanos.

Distribuídos nas três categorias mencionadas, pode-se calcular de forma aproximativa que os documentos provenientes das instâncias decisórias do poder Executivo - Departamento de Estado, Casa Branca, Conselho de Segurança Nacional e Departamento de Defesa - representam em torno de 50\%, embora isso não signifique que traduzam os processos de tomada de decisão. Aqueles vindos das instâncias intermediárias, produzidos pela embaixada dos Estados Unidos na Argentina, pela CIA e pelo Congresso estadunidense compõem aproximadamente $44 \%$ do conjunto. Por fim, somam $6 \%$ os documentos de fontes diversas, constituídos por governos estrangeiros, agências argentinas e instituições financeiras internacionais.

Quanto ao recorte temporal, a documentação vai do ano da morte de Juan Perón, em 1974, quando instalou-se na Argentina uma crise política de graves proporções, até 1980, final da administração de Jimmy Carter. Praticamente não cobre, portanto, eventos importantes como a Guerra das Malvinas (1982) ou a passagem para a democracia (1984). Nesse intervalo, 24\% equivalem ao final da administração de Richard Nixon e à administração de Gerald Ford, aproximadamente $74 \%$ correspondem ao governo Jimmy Carter e apenas $2 \%$ referem-se a um período posterior. $^{17}$

\section{Brasil}

A desclassificação por parte da administração de Barack Obama de documentos relativos ao Brasil respondeu a um apelo da Comissão Nacional da Verdade, em agosto de 2012. Na carta dirigida ao presidente estadunidense, solicitouse o acesso a documentos do Departamento de Estado, do Departamento de Defesa,

\footnotetext{
${ }^{17}$ Em viagem à Argentina realizada pelo presidente Barack Obama em abril de 2016, foi anunciado um novo projeto de desclassificação de documentos, dessa vez envolvendo agências outrora recalcitrantes como a CIA, o FBI e o Departamento de Defesa. (OSÓRIO, NSA, EBB 545) Sua continuidade foi assegurada pelo presidente Donald Trump, tendo sido liberados 931 documentos. (OSÓRIO, NSA, EBB 588)
}

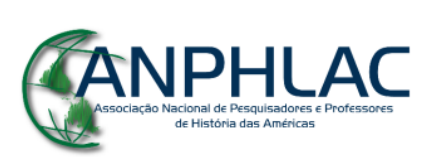


da CIA, do Conselho de Segurança Nacional, da Agência para o Desenvolvimento Nacional e do FBI (CNV, Ofício 26, 2012). O pedido não se concentrou na política externa dos Estados Unidos em relação ao Brasil, mas na repressão e na violência política, com foco em uma lista de vítimas, em alguns casos paradigmáticos de atores políticos e órgãos que tiveram papel destacado na violência política do período. (CNV, 2012) Em setembro do ano seguinte, o ex-consultor da Agência de Segurança Nacional (National Security Agency), Edward Snowden, revelou publicamente, com a ajuda dos jornalistas Glenn Greenwald e Sônia Bridi, documentos ultrassecretos que indicavam que a Agência mantinha espionagem sobre a presidenta Dilma Rousseff e seus principais assessores, assim como sobre o presidente do México, Enrique Peña Nieto. (G1, 2013) O caso, divulgado no programa Fantástico e pela imprensa nacional e internacional, gerou uma crise nas relações entre os Estados Unidos e o Brasil que se arrastaria por meses, comprometendo o projeto de desclassificação dos documentos brasileiros.

Em junho de 2014, o vice-presidente dos Estados Unidos, Joe Biden, visitou o Brasil e uma leva de 43 documentos foi encaminhada ao país como um gesto diplomático no sentido de retomar as relações amistosas entre os dois países. (BYRNE, 2014) A segunda leva, com 113 documentos, foi entregue à Comissão Nacional da Verdade apenas em dezembro de 2014, mês em que o relatório final da Comissão foi apresentado à presidenta Dilma Rousseff e à sociedade brasileira, de modo que as informações contidas nos documentos não puderam ser aproveitadas nas investigações da CNV. A terceira remessa, com 538 documentos, foi entregue apenas em 30 de junho de 2015, durante a visita da presidenta brasileira aos Estados Unidos. (CNV, 2015) Embora o prosseguimento do projeto tenha tido por intenção o desenvolvimento de uma "diplomacia da desclassificação", os documentos chegaram tarde demais para serem aproveitados pela $\mathrm{CNV}$ e colocaram à disposição do público uma quantidade de material muito inferior a dos projetos do Chile e mesmo da Argentina.

A documentação não foi indexada, de modo que não há dados disponíveis sobre a quantidade de documentos correspondente a cada agência de origem. Ainda que provenham de várias fontes, a ampla maioria dos documentos refere-se a relatórios e informações sobre a violência política e pouco contemplam o tema da

\section{GANPHLAC}

Revista Eletrônica da ANPHLAC, ISSN 1679-1061, №. 25, p. 275-302, Jul./Dez., 2018.

http://revista.anphlac.org.br 
política externa dos Estados Unidos em relação ao Brasil. Como ocorre com outras coleções, há vários documentos com trechos censurados, mas chama a atenção a existência de alguns cujas tarjas chegam a cobrir $80 \%$ ou $95 \%$ do texto.

O recorte cronológico cobre o período da ditadura militar brasileira, de 1964 a 1985. Do total de 694 documentos, aproximadamente $18 \%$ referem-se à administração Lyndon Johnson, 60\% às de Richard Nixon e Gerald Ford, 10\% à de Jimmy Carter, $11 \%$ à de Ronald Reagan e 1\% aos períodos anteriores a 1964 ou posteriores a 1985.

$$
* * *
$$

A documentação mais abundante corresponde aos períodos de maior repressão política que coincidiu, nos casos do Brasil e do Chile - e mesmo em parte ao da Argentina, no momento logo anterior ao golpe e nos meses que se seguiram - ao das administrações de Richard Nixon e Gerald Ford. Isso se explica em grande medida em razão foco do NSA na investigação de violações dos direitos humanos. Decorre igualmente do método de coleta de documentação adotado pela instituição, que consiste em buscar nos diversos arquivos estadunidenses material em torno de acontecimentos e atores políticos emblemáticos. A estratégia de pesquisa é certamente válida, sobretudo para a identificação de documentos que trazem informações inéditas sobre um determinado processo político crucial ou um caso de violência contra uma vítima conhecida. Nesse sentido, são elaborados sob medida para atrair a atenção da imprensa, e mesmo do público, sobre um assunto específico, divulgado no site com uma breve contextualização histórica e um conjunto de documentos. Contudo, o procedimento estabelece um viés do qual o pesquisador precisa ter consciência, dificultando, por exemplo, uma investigação de caráter mais sequencial ou quotidiano das relações dos Estados Unidos com esses países, ou o estudo de temas não priorizados pelos analistas do NSA. O caráter político desses acervos merece reflexão do pesquisador, em termos de quais foram os documentos solicitados pela NSA e/ou por outros atores sociais, quais foram os liberados pelas diferentes agências governamentais - apreciando quais colaboraram e quais se recusaram a fornecer material -, em que conjuntura política a documentação foi disponibilizada, ou como o

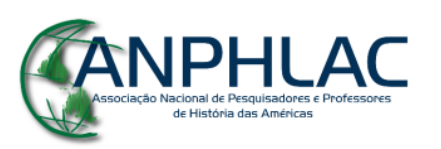


processo incidiu na relação bilateral dos Estados Unidos com outros países envolvidos.

\section{Desafios metodológicos}

Pela forte carga política que tanto o tema das ditaduras militares quanto o das relações dos Estados Unidos com os países da América Latina encerram, ambos com ressonâncias em debates políticos do presente, a lida com essas fontes implica em precauções metodológicas. As mais evidentes, que são generalizáveis para qualquer contexto de pesquisa histórica, consistem em evitar encaixar os acontecimentos em uma teoria ou conjunto de hipóteses pré-definido, ou, no outro extremo, perfilar longas sequências de acontecimentos desprovidas de uma análise dos processos e tendências de fundo que os animam. (TRACHTENBERG, 2006, p. 33) Se as descobertas importantes de pesquisa são aquelas que desafiam o senso comum, como defende Marc Trachtenberg (2006, p. 38), há de se fazer prova de abertura de espírito para não passar por cima de evidências que demonstram eventos inesperados, que contradizem nossas hipóteses iniciais e sobretudo para integrar as tensões, por exemplo, entre uma política de abertura dos países do Cone Sul para o capital externo e o nacionalismo de determinados setores das Forças Armadas em questões de ordem política. $^{18}$

A seguir, quatro desafios metodológicos serão examinados:1. a integração das diferentes temporalidades históricas; 2. as relações entre indivíduos e estruturas; 3. o peso das fronteiras nacionais em um fenômeno com cortes regionais e transnacionais; 4. a avaliação equilibrada do papel dos Estados Unidos.

\section{Pluralidade dos ritmos}

Os documentos da diplomacia estadunidense conjugam preocupações pontuais - como o entendimento de determinado fato político ocorrido em outro país ou uma decisão sobre a melhor política a adotar - com relatórios que pretendem estabelecer

\footnotetext{
${ }^{18}$ A obra de Trachtenberg é um excelente guia de pesquisa. Sobre as estratégias para lidar com os documentos de arquivo propriamente ditos, ver especialmente o capítulo 5, Working with documents (Trachtenberg, 2006).
}

\section{CANPHLAC}

Revista Eletrônica da ANPHLAC, ISSN 1679-1061, №. 25, p. 275-302, Jul./Dez., 2018.

http://revista.anphlac.org.br 
um quadro de análise mais amplo, com o intento de compreender as raízes mais profundas de uma tendência ou processo político. Se os segundos nos dão acesso às concepções mais gerais dos funcionários estadunidenses a respeito da história dos países do Cone Sul, são os primeiros que nos informam detalhes importantes, como as discordâncias entre diferentes agências da política externa estadunidense e as razões pelas quais tal ou qual rumo foi adotado.

Tomemos como exemplo os debates ocorridos no interior do governo Nixon em torno do curso de ação a seguir diante da posse do governo Allende. As discussões nos bastidores demonstram que não havia consenso quanto à proposta de desferir um golpe em 1970. Não havia no Chile um quadro no qual interesses vitais estadunidenses estariam sendo ameaçados para justificar uma ação de força que traria consequências extremamente negativas para a diplomacia. É nesse nível da história mais imediata que se pode observar os dilemas da diplomacia estadunidense, obscurecidos em boa parte das vezes por um padrão de ação que indica mais as continuidades do que as ponderações. Mesmo que essas preocupações não chegassem a impedir o prosseguimento de uma política mais previsível pelos padrões anteriores, é significativo saber que os agentes diplomáticos tinham consciência do preço que pagavam pela condução agressiva dos Estados Unidos de sua política externa. Entre eles, o do país se tornar "refém" dos setores apoiados, como ocorreu quando, após validar publicamente o golpe no Brasil, o país viu-se associado a uma série de medidas autoritárias deflagradas pelo aliado. ${ }^{19}$ É ainda nesse plano da discussão do dia-a-dia dos bastidores que tomamos conhecimento da consciência de que a estratégia adotada em Cuba, levando a ilha a associar-se ao campo soviético, fora um erro. (KORNBLUH, 2013, p. 9) Se os importantes detalhes dos bastidores têm o condão de nos abrir as portas para aquilo que não consta nos discursos oficiais, tomados exclusivamente nos conduzem a perder o quadro mais geral de tendências e conjunturas de maior complexidade.

O segundo plano a ser integrado na análise desses documentos é o da Guerra Fria, com a importante reconfiguração do papel internacional dos Estados Unidos, o realinhamento mundial a partir do conflito bipolar, e suas significativas consequências

\footnotetext{
${ }^{19}$ Efeito que um especialista do Departamento de Estado lamentou no final de 1968, ao afirmar que os Estados Unidos deveriam ter se afastado do Brasil em 1965, quando da promulgação do Ato Institucional no 2. (NARA, RG 59, 1967-69, POL 23-9 BRAZ, doc 241)
}

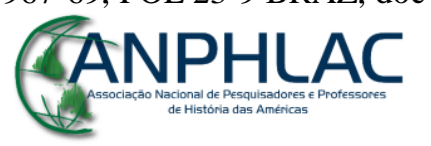

Revista Eletrônica da ANPHLAC, ISSN 1679-1061, №. 25, p. 275-302, Jul./Dez., 2018.

http://revista.anphlac.org.br 
para o subcontinente latino-americano. A Revolução Cubana de 1959, seguida da guinada em direção ao socialismo em 1961, é um produto interessante do cruzamento entre longa e média duração, entre o nacional e o quadro internacional. Se a revolução, como diversos autores proclamam, (FERNANDES, 1979; LOWY, 2006; BANDEIRA, 2008) foi produto de um contexto local, fruto de uma sociedade profundamente desigual assentada no domínio das oligarquias e do capital estadunidense, a Guerra Fria foi o elemento crucial para que a rebeldia da ilha se sustentasse por décadas. Afinal, sem a parceria econômica com a União Soviética, é fácil prever que o destino cubano teria sido semelhante ao da Guatemala em 1954, quando a CIA promoveu uma operação secreta levando à derrubada do presidente Jacobo Arbenz.

A Revolução Cubana foi um marco na política do governo Kennedy no sentido de se aproximar dos militares da região por considerá-los parceiros confiáveis para a política estadunidense de contenção ao comunismo. A dinâmica interamericana da Guerra Fria completa esse quadro com o esforço concertado das elites da região para evitar a ascensão e permanência no poder de governos com perfil reformista ou socialista. (McSHERRY, 2005) É nesse plano que podemos compreender as continuidades da política externa para a América Latina de governos que, na esfera doméstica estadunidense, tiveram perfis consideravelmente distintos, como John Kennedy, Lyndon Johnson, Richard Nixon e Gerald Ford. Ou o fato de a política externa centrada no respeito dos direitos humanos de Jimmy Carter ter se orientado para uma versão mais "pragmática" na segunda metade de seu mandato. (SIKKINK, 2004)

Em terceiro plano, inscrito em uma duração mais longa, temos a política externa dos Estados Unidos em relação à América Latina. Lars Schoultz em seu livro Estados Unidos: poder e submissão, explica como o projeto de hegemonia do país do norte ao longo dos século 19 e 20 apoiou-se não apenas em interesses geopolíticos e econômicos, mas também em um profundo preconceito contra as populações latinoamericanas. Diane Kunz reforça o argumento:

“[...] para os diplomatas a América Latina continuava a ser a área mais importante do mundo em desenvolvimento. Cento e quarenta anos de Doutrina Monroe criaram uma mentalidade

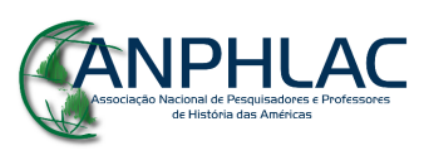

Revista Eletrônica da ANPHLAC, ISSN 1679-1061, №. 25, p. 275-302, Jul./Dez., 2018.

http://revista.anphlac.org.br 
que aceitava com dificuldade a autonomia das nações latinoamericanas". ${ }^{20}(1994$, p. 8$)$

Adquirindo formas variadas, entre a formulação - na época de efeito apenas retórico do slogan “A América para os americanos", da Doutrina Monroe (1823), passando pela guerra Mexicano-Americana (1846-1848), pelo Pan-Americanismo (1889-1892), pelas múltiplas ingerências na América Central, pela Política do Big Stick (19011909) e pela Diplomacia do Dólar (1909-1913) e mesmo pela entrada massiva no mercado de entretenimento que marcou o período da Política de Boa Vizinhança (1933-1945) e enfim, no pós-guerra, pela Doutrina de Segurança Nacional, temos a presença constante de um esforço dos Estados Unidos para impor e manter sua hegemonia política, econômica e cultural na região. (SANTOS, 2007) No plano de longo fôlego, as ditaduras militares inserem-se no continuado processo das elites latino-americanas de manter seu poder e evitar reformas populares que levassem a uma distribuição justa das riquezas nacionais. Nesse esforço, não raro a aliança com os Estados Unidos foi um trunfo de setores da elite dirigente, fenômeno que ajuda a explicar a longevidade do imperialismo.

Esse plano é de grande importância, entretanto, tomado isoladamente impede a percepção de um relevo muito mais complexo. Se os diversos programas voltados para a América Latina tinham como pressuposto a hegemonia estadunidense, a diferença de seus contornos e métodos é mais do que significativa e precisa ser levada em conta. No período que nos ocupa, a despeito das continuidades, é fundamental, por exemplo, apontar as diferenças entre as administrações Nixon e Carter, em termos de princípios, concepções e mesmo de práticas. Do mesmo modo, deve-se lembrar da existência nos Estados Unidos de uma "cultura política democrática e antiimperialista, multicultural e pluralista", que de diversos modos e em contextos históricos variados buscou contrapor o unilateralismo da política externa, bem como a

\footnotetext{
${ }^{20}$ (Tradução minha.) No original: “[...] to American diplomats Latin America remained the most important area of the developing world. One hundred forty years of the Monroe Doctrine had created an American mind set that found difficulty accepting the autonomy of Latin American nations." Ressalva seja feita para o fato de que a Doutrina Monroe, criada em 1823, no contexto da Santa Aliança, para responder a questões do início do século XIX, teve na época efeito meramente simbólico. Ela é associada anacronicamente à política imperialista dos Estados Unidos devido à sua evocação pela política externa de Theodor Roosevelt (1901-1909). O Corolário à Doutrina Monroe (1904), por ele instituído, estabelecia a intervenção dos Estados Unidos nos países do continente como último recurso para garantir que cumprissem suas obrigações vis-à-vis de credores internacionais, com o intuito de evitar agressões de países externos à região.
}

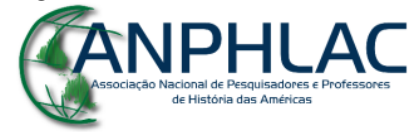

Revista Eletrônica da ANPHLAC, ISSN 1679-1061, №. 25, p. 275-302, Jul./Dez., 2018.

http://revista.anphlac.org.br 
noção de excepcionalidade e superioridade dos estadunidenses. (AZEVEDO, 2004, P. $15)$

Assim, observar o entroncamento desses três planos é fundamental para não se perder nos vai-e-vens do quotidiano da administração diplomática, ou em afirmações generalistas que impeçam um conhecimento mais aprofundado e contrastado da política externa estadunidense em relação ao Cone Sul. Integrar as políticas efetivamente aplicadas às hesitações, dilemas, contradições, conflitos e recuos, dimensionando a importância histórica de cada elemento, é um dos grandes desafios que nos coloca essa documentação.

\section{Indivíduos e estruturas}

É difícil menosprezar o papel que alguns personagens dessa história desempenharam nas relações estadunidenses com as ditaduras militares. O adido militar Vernon Walters é um desses casos. Convencido do risco que representava o presidente brasileiro eleito João Goulart aos interesses estadunidenses, Lincoln Gordon, então embaixador no Brasil, persuadiu John Kennedy - sem muito trabalho, é certo - de que era necessário "fortalecer a espinha dos militares", encontrando para tal tarefa um adido militar que realizasse a aproximação necessária. (NSA, EBB n. 465, doc 1, p. 19) Walters havia lutado ao lado dos brasileiros na Segunda Guerra Mundial, tornando-se próximo de Castelo Branco, general que viria a ser o primeiro presidente da ditadura militar brasileira. Foi uma figura decisiva na articulação do golpe e defendeu a proximidade dos Estados Unidos com a ditadura brasileira após serem tomadas as medidas repressivas que prejudicariam a imagem do país no exterior. Após sua missão no Brasil, Walters tornou-se vice-diretor da CIA e foi o contato chave do coronel chileno Manuel Contreras no recrutamento de agentes de alto nível da agência estadunidense para treinar quadros que integrariam a Dirección de Inteligencia Nacional (DINA). (DINGUES, 2004, p. 112-3)

O personagem incontornável desse período, contudo, segue sendo Henry Kissinger, o conselheiro de Segurança Nacional de Richard Nixon, que junto ao presidente assumiu o controle da política externa estadunidense. Kissinger, significativamente nomeado secretário de Estado logo após o golpe no Chile, foi um dos arquitetos da intervenção nesse país, por meio das operações encobertas da CIA.

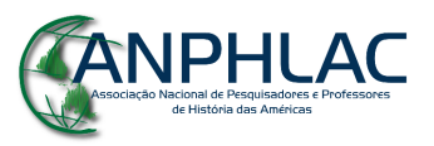

Revista Eletrônica da ANPHLAC, ISSN 1679-1061, №. 25, p. 275-302, Jul./Dez., 2018.

http://revista.anphlac.org.br 
Manteve relações próximas com o general Augusto Pinochet e assegurou aos militares argentinos que os Estados Unidos apoiariam a tomada de poder naquele país. Partidário da realpolitik, contornou como pôde os esforços do Congresso estadunidense no sentido de estabelecer limites à ajuda externa econômica e militar a países autoritários. Teve, contudo, menos sucesso quando não contava com o poderoso aval de seu superior hierárquico, caso de seus esforços de retomar o diálogo com Cuba. Segundo William Leogrande e Peter Kornbluh, Kissinger, em sua estratégia de détente com a União Soviética, buscou uma abertura em relação a Cuba como fez em direção à China. (2015, Cap. 4) Sua grande capacidade de convencimento e articulação não foi suficiente, contudo, para contornar a obstinada oposição de Richard Nixon a normalizar as relações entre os dois países, o que nos leva a considerar os limites estruturais, mas também conjunturais colocados a esses personagens.

Por mais que figuras como Walters e Kissinger tenham contribuído ativamente para sustentar uma política externa de fomento a golpes militares no Cone Sul e de apoio estadunidense às ditaduras que se seguiram, não há como saber quão diferentes poderiam ter sido os acontecimentos sem sua participação. Mas vale lembrar que John Kennedy e Lincoln Gordon teriam encontrado algum outro adido que falasse português, que a conspiração golpista tinha por núcleo as elites nacionais e que qualquer outro diretor da CIA seguramente apoiaria o treinamento dos agentes da polícia política chilena. Do mesmo modo, Henry Kissinger foi uma peça fundamental na política externa de Richard Nixon, mas é difícil imaginar que o presidente do Watergate não fosse buscar alguém com perfil agressivo e proativo para pôr em prática suas concepções de falcão da Guerra Fria. Lembremos que Ronald Reagan não precisou de Kissinger, nos anos 1980, para fomentar os golpes militares da América Central. ${ }^{21}$ Assim, a importância desses indivíduos situa-se menos na direção geral que os rumos da política externa estadunidense tomaram que nos caminhos percorridos.

\footnotetext{
${ }^{21}$ Kissinger foi nomeado membro do Conselho Consultivo de Inteligência Externa (Foreign Intelligence Advisory Board), do qual participou entre 1984 e 1990, mas não foi peça central na política externa de Reagan.
}

\section{CANPHLAC}

Revista Eletrônica da ANPHLAC, ISSN 1679-1061, №. 25, p. 275-302, Jul./Dez., 2018.

http://revista.anphlac.org.br 


\section{Transcender as fronteiras nacionais: um enfoque transnacional}

Conquanto os países da América Latina tenham uma tradição de voltarem-se à Europa e aos Estados Unidos e darem-se as costas uns aos outros, é inegável que em sua história atravessaram ciclos históricos semelhantes, entre os quais o das ditaduras militares. (ROUQUIÉ, 1991) Assim, abarcar o caráter regional, que supera os significados que cada ditadura teve para os estados nacionais, é importante para abranger o aspecto mais amplo dessa experiência histórica do Cone Sul, região da América Latina que compartilha uma série de características. Na documentação das agências estadunidenses, há alguns caminhos possíveis para superar a organização arquivística centrada nas fronteiras nacionais. Como afirma Barbara Weinstein (2013, p. 30), "a história transnacional é melhor entendida como uma abordagem que complica, e não desloca, a história nacional”. Caberia, portanto, complexificar as relações entre os países envolvidos, refletindo por um lado sobre circulações e interações que em matéria repressiva foram significativas e por outro em como a política externa dos Estados Unidos foi também moldada pelas experiências bem ou mal sucedidas vividas no relacionamento com as ditaduras do Cone Sul. Afinal, "as relações interamericanas não podem ser pensadas como uma rua de mão única”. (Idem, p. 20)

Há relatórios periódicos de agências como a CIA ou a Secretaria de Estado dos Assuntos Interamericanos que se debruçam sobre a região do Cone Sul ou a América Latina. Normalmente possuem uma seção que trata dos traços e tendências comuns à região e em seguida individualizam as análises para cada país. Em um desses relatórios, o secretário de Estado dos Assuntos Interamericanos adverte:

Ao discutir as características gerais dos regimes militares do sul, fizemos algumas amplas e indefensáveis generalizações. $\mathrm{O}$ que se segue é uma tentativa de corrigir as piores distorções, país por país. É importante ser claro a respeito das diferenças porque, por razões que devemos desenvolver mais tarde, nossa política deveria enfatizar o que os países não possuem em comum, mais do que o que compartilham. (NSA, AR00356, p. 7) ${ }^{22}$

\footnotetext{
${ }^{22}$ (Tradução minha.) No original: In discussing the general characteristics of the southern military regimes, we have made some indefensibly broad generalizations. The following is an attempt to correct the worst distortions, country-by-country. It is important to be clear about the differences because, for
}

\section{GANPHLAC}

Revista Eletrônica da ANPHLAC, ISSN 1679-1061, №. 25, p. 275-302, Jul./Dez., 2018.

http://revista.anphlac.org.br 
O trecho citado nos adverte que mesmo em uma análise que busque apreender as tendências gerais da região, as diferenças nacionais precisam ser a todo momento evocadas sob o risco de deixar de lado elementos cruciais para o entendimento da história do período.

A estratégia dos Estados Unidos de apoiarem-se em aliados regionais para não arcarem sozinhos como peso de sua política externa é outro elemento que chama a atenção para a dinâmica internacional. Bom exemplo disso é o relatório preparado por Vernon Walters para Henry Kissinger sobre a política a adotar em relação ao Chile de Salvador Allende. Após defender que não havia alternativa "aceitável" a não ser manter o controle sobre a América Latina - por seus recursos, pelos problemas sociais e econômicos de sua população, pela proximidade com os Estados Unidos e por seu potencial futuro - sugere dar ao Brasil e à Argentina a mesma "sensação de participação e consulta que damos a nossos aliados europeus”, explicando que ao ajudá-los poder-se-ia influenciá-los. E acrescenta: “Algum dia poderemos querer que façam algo que nós mesmos não queremos fazer. Devemos encorajá-los a cooperar uns com os outros [...] Acima de tudo, devemos manter viva a ideia de um destino comum". (NSA, CL00302) $)^{23}$

O estabelecimento de cronologias detalhadas dos acontecimentos mais relevantes para o tema para cada país e para a região ajuda a perceber os cruzamentos e os fatores de influência de um país sobre o(s) outro(s). Assim, viagens de personalidades políticas pela região, ou encontros regionais e internacionais - como as conferências da OEA, ou a Primeira Reunião de Trabalho de Inteligência Nacional, em novembro de 1975, em Santiago do Chile, que criou oficialmente a Operação Condor. A observação atenta desses eventos com consequências para vários países e a intersecção das datas permitem notar, por exemplo, que Henry Kissinger, na Assembleia Geral da OEA, ocorrida em 1976 em Santiago do Chile, desprezou quase que completamente os conselhos do Subsecretário de Estado para Assuntos

reasons we shall develop later, our policy should be to emphasize what the countries do not have in common rather that what they do.

${ }^{23}$ (Tradução minha.) No original: sense of participation and consultation as we give our European allies" [...] "Some day we may want them to do something that we ourselves do not want to do. We must encourage them to cooperate with one another [...]. Above all, we must keep alive the idea of a common destiny." (Tradução minha.) Outro excelente exemplo é a conversa entre Richard Nixon e Garrastazu Médici em 1971, na Casa Branca, Washington DC. Os dois presidentes compartilham suas impressões sobre diversos países da América Latina e prometem-se trabalhar em colaboração. (NSA, EBB n. 282, doc 1)

\section{CANPHLAC}

Revista Eletrônica da ANPHLAC, ISSN 1679-1061, №. 25, p. 275-302, Jul./Dez., 2018.

http://revista.anphlac.org.br 
Interamericanos William D. Rogers de levantar com vigor o tema direitos humanos em sua conversa com Pinochet. Reuniu-se com o ditador antes de seu discurso sobre direitos humanos para explicar que se tratava de uma concessão sem grandes consequências às pressões domésticas do Congresso e da opinião pública estadunidense e, dois dias depois, em encontro com o ministro das relações exteriores da Argentina, almirante Guzzetti, expressou as mesmas ideias que transmitira ao ditador chileno: apoiava as ditaduras e considerava que a mídia apenas estava fazendo pressão porque havia sido derrubado um governo de esquerda. (NSA, CL01418, p. 1; NSA, CL01429) Por fim, há o aspecto eminentemente transacional de alguns fenômenos que evidentemente clamam por uma abordagem que transcenda as fronteiras: é o caso dos refugiados de um país a outro e da Operação Condor, que reuniu os países da região em uma rede conjugada de informações e de ações repressivas. ${ }^{24} \mathrm{O}$ enfoque transnacional é possível na medida em que não nega a existência da nação como organizador das esferas política, econômica e cultural de um dado povo, nem prescinde da comparação como instrumento de análise, mas incorpora outros aspectos: redes, interações, processos, que interligam e ao mesmo tempo transformam os países envolvidos. (WEINSTEIN, 2013, p. 26, 31)

\section{O peso dos Estados Unidos}

O sentido da política externa dos Estados Unidos, pelo menos desde John Kennedy, de apostar nos militares como aliados naturais contra o comunismo na América Latina deixa pouca dúvida sobre o papel preponderante da potência, ainda que esteja longe de ser esgotada a tarefa de determinar de forma precisa seus alcances e limites. As fontes cobrem diferentes níveis hierárquicos e diversas agências estadunidenses. Quanto mais alto o escalão, maior a sensação de unilateralidade nas relações externas e de arrogância imperial. Casos exemplares são as instruções do presidente Lyndon Johnson no sentido de fazer tudo o que fosse necessário para derrubar seu congênere João Goulart no Brasil. (NSA, EBB n. 118, doc 1) Ou a inflamada fala de Richard Nixon sobre Salvador Allende: "Havendo qualquer maneira de feri-lo, seja por meio do governo ou de negócios privados, - quero que saibam que nossa política é desfavorável." Ainda, sua ameaça dirigida à toda a região: "Não se

${ }^{24}$ Sobre Condor, ver CALLONI, 2004; McSHERRY, 2005.

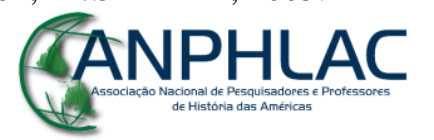

Revista Eletrônica da ANPHLAC, ISSN 1679-1061, №. 25, p. 275-302, Jul./Dez., 2018.

http://revista.anphlac.org.br 
deve permitir a impressão na América Latina que eles podem se livrar com isso, de que é seguro ir por esse caminho." (NSA, CL00309) ${ }^{25}$

No entanto, a maior parte das fontes desclassificadas provém de funcionários intermediários, cuja função não era a de determinar qual seria a política estadunidense em relação ao país em que se servia, e sim reportar o que estava ocorrendo, analisar a situação e, eventualmente, sugerir medidas, fornecendo dados que informariam o processo decisório. Por isso essa documentação não é apenas preciosa para o estudo das relações externas dos Estados Unidos com as ditaduras, mas para o conhecimento dos bastidores do poder, ao qual os agentes estadunidenses tinham privilegiado acesso. Pela mesma razão, fornece informações por vezes inacessíveis em outros acervos, uma vez que é prática de governos autoritários esconder ou destruir documentos que dão testemunhos de suas práticas violentas e ilegais. Provém desse acervo, por exemplo, uma descrição bastante detalhada dos métodos violentos de interrogatório praticados no Brasil. (NSA, EBB n. 478, doc 1) Assim como a informação de que a ordem do ataque ao ex-ministro chileno Orlando Letelier em Washington DC, em setembro de 1976, partiu do próprio Augusto Pinochet. (NSA, EBB n. 532, doc 1)

Os documentos diplomáticos e das agências de inteligência mostram a extensa e variada rede de conexões das embaixadas e consulados estadunidenses nesses países, com informantes e fontes - nem sempre revelados - que cobrem um amplo espectro político e ideológico, de estudantes e intelectuais de esquerda às altas hierarquias do governo militar, passando por empresários, jornalistas e agentes repressivos. Os funcionários estadunidenses tinham acesso privilegiado aos membros dos órgãos repressivos e, no caso do Brasil ao menos, alguns chegaram a frequentar suas instalações. ${ }^{26}$ Isso não significa, porém, que não ficassem no escuro em diversas situações. Esses acervos abrigam relatórios que demonstram incerteza sobre o número

\footnotetext{
${ }^{25}$ (Tradução minha.) No original: "If there is any way we can hurt him whether by government or private business - I want them to know our policy is negative." e sua ameaça dirigida à toda a região: "No impression should be permitted in Latin America that they can get away with this, that it's safe to go this way."

26 "No Brasil da década de 1970, agentes e diplomatas dos Estados Unidos conviviam com serviços do DOPS de São Paulo. De acordo com livros da portaria do DOPS [Departamento de Ordem Política e Social] que foram disponibilizados recentemente, os diplomatas Claris Rowley Halliwell, Frederic Lincoln Chapin e C. Harlow Duffin frequentavam o prédio do DOPS em São Paulo. Halliwell, political officer do consulado americano, fez 49 visitas ao DOPS entre 1971 e 1974." (CNV, 2014, Vol. 1, p. 232-3)
}

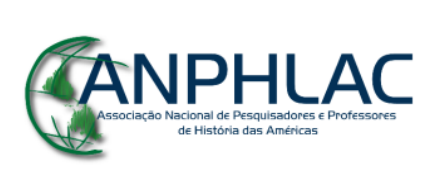


de presos políticos no Brasil após o golpe, dúvidas sobre o grau de autonomia operacional das forças repressivas na Argentina, ou sobre a existência ou não de uma operação concertada entre as nações do Cone Sul voltada à perseguição política. Muitas dessas questões foram se esclarecendo ao longo do tempo, mas sua existência demonstra os limites da diplomacia em seu esforço de se manter bem informada.

A pesquisa nessas fontes conduz também à relativização da imagem da onipotência estadunidense. Em primeiro lugar, por seus erros, cujo exemplo clássico é a tentativa de invasão da Baía dos Porcos em Cuba, em 1961. Outro caso foi a tentativa malsucedida de neutralizar o general legalista René Schneider, comandante em chefe do Exército chileno, em outubro de 1970. A operação resultou em seu assassinato, o que por sua vez causou comoção nacional e resultou em uma ratificação majoritária de Allende no Congresso. Foi igualmente fracassado o investimento massivo na oposição a Allende nas eleições legislativas chilenas, em março de 1973, com vistas a obter maioria de dois terços contrários ao governo e com isso deflagrar um impeachment constitucional do presidente. Disputas internas, como as que ocorreram entre a Secretaria de Direitos Humanos, carro-chefe da aplicação da nova orientação do governo Jimmy Carter para a política externa estadunidense e a Secretaria de Estado para Assuntos Interamericanos, defensora da abordagem tradicional da Guerra Fria, demonstram que em algumas circunstâncias as agendas de diferentes agências não confluíam, o que causava conflitos e acarretava em dificuldades para estabelecer um curso definido de ação.

Outro elemento que mostra as limitações do poder estadunidense na região é o preço a pagar pelo comprometimento da retórica da defesa incondicional da liberdade e da democracia com a associação da imagem do país à violenta repressão política praticada pelas ditaduras do Cone Sul. O contraste entre discurso e prática era particularmente agudo em um período em que, nos Estados Unidos, o tema dos direitos humanos estava em franca erupção, manifestando-se, entre outras maneiras, por um ativismo inédito do Congresso estadunidense no sentido de evitar o apoio do país a governos autoritários. (ECKEL, MOYN, 2014) Ao mesmo tempo a documentação demonstra o embaraço dos funcionários diplomáticos no sentido de pressionar os governos dos países em que serviam para diminuir o grau de violações aos direitos humanos com vistas a preservar uma boa imagem no exterior. Fica

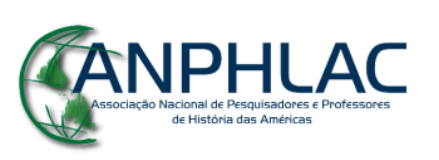

Revista Eletrônica da ANPHLAC, ISSN 1679-1061, №. 25, p. 275-302, Jul./Dez., 2018.

http://revista.anphlac.org.br 
evidente que os militares não levavam muito a sério as investidas desses agentes, uma vez que acreditavam estar seguindo ao pé da letra as orientações estadunidenses de acabar com o comunismo e a insurgência em seus países.

Enfim, são notáveis as restrições do poder estadunidense nos momentos em que não houve confluência de agendas entre os Estados Unidos e as ditaduras militares, o que ocorreu durante o governo de Jimmy Carter, eleito com a promessa de promover uma política externa centrada nos direitos humanos. No caso da Argentina, Kathrin Sikkink relata que diante do anúncio do Secretário de Estado Cyrus Vance, em fevereiro de 1977, de que haveria uma redução da ajuda militar no ano seguinte em razão de abusos dos direitos humanos, “A Argentina reagiu indignada, afirmando que essa ação era interferência indevida em seus assuntos internos e rejeitou o que restava da ajuda militar dos EUA" (SIKKINK, 2004, p. 131) ${ }^{27}$ Apesar de algumas conquistas importantes da administração Carter, segundo Marcos Novaro: "[...] el gobierno argentino no se amoldó a las presiones. Si hizo algunas concesiones, [...] fueron muy menores y distractivas en relación al problema fundamental que eran los secuestros y las desapariciones." (NOVARO, 2011, p. 120) ${ }^{28}$ Outro episódio interessante, já no governo de Ronald Reagan, ilustra não apenas os limites das pressões estadunidenses, como os efeitos "colaterais" da política de apoio às ditaduras militares. Em um memorando endereçado ao presidente, o secretário de Estado George P. Shultz queixa-se de que:

Estamos caminhando para um período de $12-18$ meses
extremamente difícil com o Chile. O presidente Augusto
Pinochet está determinado a suceder a si mesmo como
presidente por todos os meios necessários para garantir seu
sucesso. Excluiu a possibilidade de eleições livres e abertas e
ao invés disso pretende seguir com um plebiscito envolvendo
um único candidato - ele mesmo. As consequências dessa
permanência no poder seriam altamente perigosas para o
Chile e a região com um todo; inevitavelmente conduziria a
uma séria polarização da população chilena e anum reforço 27 (Tradução minha.) No original: "Argentina reacted angrily, claiming that this action was undue
interference in its internal affairs, and rejected the remaining U.S. military aid.."
28 (Tradução minha.) No original: "[...] o governo argentino não se submeteu às pressões. Se fez
algumas concessões, [...] foram muito reduzidas e diversionistas em relação ao problema fundamental
que eram os sequestros e os desaparecimentos". O governo dos Estados Unidos conseguiu, contudo,
que a Comissão Interamericana de Direitos Humanos (CIDH) visitasse o país, o que resultou em um
considerável desafio à ditadura argentina. Para um relato circunstanciado da visita da CIDH, discutindo
as questões em jogo para a política interna argentina, ver NOVARO, 2011, p. 117-157.

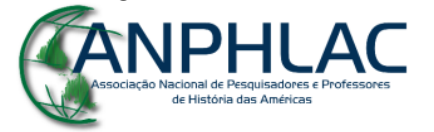

Revista Eletrônica da ANPHLAC, ISSN 1679-1061, №. 25, p. 275-302, Jul./Dez., 2018.

http://revista.anphlac.org.br 
significativo do grande (e em crescimento, graças a Pinochet), do partido comunista, dependente de Moscou. ${ }^{29}$

E em seguida acrescenta: “[...] esse é um exemplo flagrante do envolvimento direto de um chefe de Estado em um ato de terrorismo de Estado, particularmente inquietante tanto porque ocorreu em nossa capital, quanto por seu governo ser geralmente considerado amigável"30 (NSA, EBB n. 532, doc 3)

A assimetria de poder econômico, político e militar entre os Estados Unidos e os países do Cone Sul é inegável e os auxílios financeiros e militares percorriam o sentido norte-sul e não o inverso. Há de se mencionar também o prestígio no cenário internacional da grande potência, cujo apoio político assegurava tranquilidade diplomática e comercial às ditaduras militares. No sentido inverso, porém, contando com a aliança com países da região que considerava sua primeira área de influência e dependendo do alinhamento desses à sua geopolítica, os Estados Unidos não pouparam esforços para obter ambos.

$$
* * *
$$

As coleções documentais aqui problematizadas, além de possuírem inegável valor para a pesquisa histórica, ajudaram a embasar processos judiciais relativos à violação dos direitos humano no Chile e na Argentina e tiveram originalmente por objetivo contribuir para o relatório final da Comissão Nacional da Verdade do Brasil. Se as razões por parte do governo estadunidense para desclassificar esse material, bem como a metodologia de seleção dessas coleções foi semelhante - derivada do savoir faire desenvolvido pelos pesquisadores do NSA -, as circunstâncias da liberação dos documentos e seus critérios políticos variaram consideravelmente. A despeito das diferenças, buscou-se aqui abordar algumas das complexidades comuns às três coleções documentais no estudo do tema das relações das agências

\footnotetext{
${ }^{29}$ (Tradução minha.) No original: We are heading into an extremely difficult 12-18 month period with Chile. President Augusto Pinochet is determined to succeed himself as President by whatever means will ensure success. He has ruled out the possibility of a free and open election and instead intends to proceed with a yes/no plebiscite involving a single candidate - himself. The consequences of his staying in office would be highly dangerous for Chile and the region as a whole; inevitably, it would lead to serious polarization of the Chilean population and a significant strengthening of the large (and growing, thanks to Pinochet), Moscow-dependent communist party."

30 (Tradução minha.) No original: "[...] this is a blatant example of a chief of state's direct involvement in an act of state terrorism, one that is particularly disturbing both because it occurred in our capital and since his government is generally considered to be friendly."
}

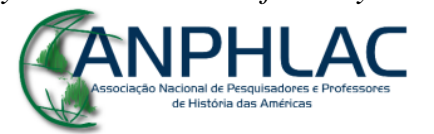

Revista Eletrônica da ANPHLAC, ISSN 1679-1061, №. 25, p. 275-302, Jul./Dez., 2018.

http://revista.anphlac.org.br 
governamentais estadunidenses com as ditaduras militares do Brasil, do Chile e da Argentina.

A importância desses acervos não anula o fato de que há uma quantidade enorme de documentos ainda sob sigilo que contribuiriam para esclarecer episódios que permanecem pouco conhecidos dessa história. Sem mencionar o fato de que nem tudo foi documentado, sobretudo no que diz respeito à repressão política e a operações encobertas conduzidas pelas agências de inteligência estadunidenses. ${ }^{31} \mathrm{Em}$ particular, é necessário investigar melhor o papel que tais agências tiveram, sobretudo em termos de know how, na estruturação de agências de inteligência e repressão, como a DINA no Chile ou o Centro de Informações do Exército no Brasil. Assim como averiguar qual foi o desempenho do treinamento ministrado pelas forças armadas dos Estados Unidos a essa geração de militares sul-americanos bem como os efeitos concretos dessa ligação por vias militares. Pesquisas que importam porque ao mesmo tempo em que poderão conduzir a um conhecimento mais preciso sobre a extensão e a intensidade da estratégia estadunidense de fomentar e apoiar ditaduras militares no Cone Sul, ajudarão ao mesmo tempo a apontar para os recursos que esses países colocaram em marcha por si mesmos, perceber em que medida as intervenções estadunidenses foram impostas ou reclamadas e identificar o protagonismo que outros países da região, como o Brasil, tiveram nesse contexto regional, desmistificando a imagem da onipotência estadunidense sem minimizar a atuação do "grande irmão".

\section{Fontes}

COMISSÃO NACIONAL DA VERDADE. A line to key cases, victimes, relevant actors and institution. 16 ago. 2012. Disponível em:

http://cnv.gov.br/images/pdf/docs/OFI_CNV_OBAMA.pdf. Acesso em: mar. 2016.

COMISSÃO NACIONAL DA VERDADE. Ofício 26/2012. Carta ao presidente Barack Obama. 10 jul. 2012. Disponível em:

http://cnv.gov.br/images/pdf/docs/OFI_CNV_OBAMA.pdf. Acesso em: mar. 2016.

\footnotetext{
${ }^{31}$ David F. Schmitz, que estudou as relações do governo estadunidense com ditaduras militares de direita de todos os continentes, afirma que o exato papel dos Estados Unidos nos golpes da Grécia, Indonésia, e até mesmo no Chile, com toda a documentação que foi desclassificada, é impossível de determinar em toda sua extensão, porque não dispomos de toda a documentação necessária. (2006, p. $48,64,101)$.
}

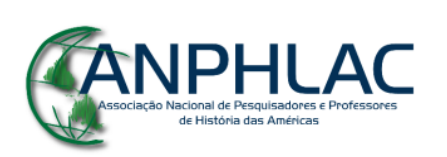


COMISSÃO NACIONAL DA VERDADE. Documentos recebidos dos EUA. 14 ago. 2015. Disponível em: http://cnv.gov.br/todos-volume-1/648-documentossss-eua-i6.html. Acesso em: mar. 2016.

COMISSÃO NACIONAL DA VERDADE. Relatório final da Comissão Nacional da Verdade. Brasília, Presidência da República, 2014.

National Archives and Records Administration, RG 59, Central Files 1967-69, POL 23-9 BRAZ. Documento 241. Telegram fromthe Department of State to the embassy in Brazil. 25 dez. 1968. Disponível em: http://20012009.state.gov/r/pa/ho/frus/johnsonlb/xxxi/36293.htm. Acesso em: mar. 2016.

National Security Archive. ARA monthly report. The third world war and South America. 3 ago. 1976. AR00356. CL01472, p. 7.

National Security Archive. Electronic Briefing Book n ${ }^{\circ} 118$, Documento 1. White House Audio Tape, President Lyndon B. Johnson discussing the impending coup in Brazil with Undersecretary of State George Ball, March 31, 1964. Disponível em: http://nsarchive.gwu.edu/NSAEBB/NSAEBB118/index.htm\#2. Acesso em: mar. 2016.

National Security Archive. Electronic Briefing Book n ${ }^{\circ} 478$, Documento 3. Department of State, "Widespread Arrests and Psychophysical Interrogation of Suspected Subversives," Confidential, 18 abr. 1973. Disponível em; http://nsarchive.gwu.edu/NSAEBB/NSAEBB478/docs/doc1.pdf. Acesso em: mar. 2016.

National Security Archive. Electronic Briefing Book $n^{\circ}$ 532, Documento 1. DOS, "Pinochet and the Letelier-Moffitt Murders: implications for US Policy", Secret. memorandum for the President. 6 out. 1987. Disponível em;

http://nsarchive.gwu.edu/NSAEBB/NSAEBB532-The-Letelier-Moffitt-AssassinationPapers/letelierdocument.pdf. Acesso em: mar. 2016.

National Security Archive. Electronic Briefing Book $n^{0}$ 465, documento 1. White House, Transcript of Meeting between President Kennedy, Ambassador Lincoln Gordon and Richard Goodwin, July 30, 1962. p. 19. Disponível em: http://nsarchive.gwu.edu/NSAEBB/NSAEBB465/docs/Document\%201\%20kennedy \%20brazil\%20meeting\%20July\%2030,\%201962.pdf. Acesso em: mar. 2016.

National Security Archive. Memorandum for Dr. Kissinger. Courses in Latin America. 3 nov. 1970. CL00302.

National Security Archive. Memorandum of conversation. Henry Kissinger's meeting with admiral Guzzetti. 10 jun. 1976. AR00291.

National Security Archive. Memorandum of conversation. NSC meeting - Chile. 6 nov. 1970, CL00309.

National Security Archive. Memorandum of conversation. U.S.-Chile relations. 8 jun. 1976. CL01429.

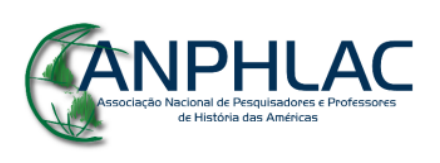

Revista Eletrônica da ANPHLAC, ISSN 1679-1061, №. 25, p. 275-302, Jul./Dez., 2018.

http://revista.anphlac.org.br 
National Security Archive. Memorandum. Overall objectives for your visit to Santiago. 26 maio 1976, CL01418.

National Security Archives. Electronc Briefing Book $n^{0}$ 282, Document 1 . White House Memorandum, Top Secret, "Meeting with President Emílio Garratazú Médici of Brazil," 9 dez. 1971. Disponível em:

http://nsarchive.gwu.edu/NSAEBB/NSAEBB282/Document\%20143\%2012.9.71.pdf. Acesso em: mar. 2016.

\section{Referências bibliográficas}

AZEVEDO, Cecília. Culturas políticas em confronto: A política externa norteamericana em questão. Anais Eletrônicos do VI Encontro da ANPHLAC, Maringá, 2004, p. 1-15.

BANDEIRA, Luiz Alberto Moniz. De Martí a Fidel. La Revolución cubana y América Latina. Buenos Aires: Norma, 2008.

BYRNE, Malcolm. Declassified diplomacy with Brazil: National Security Archive hails Obama administration decision to assist Brazilian commission. Disponível em: https://nsarchive.wordpress.com/2014/06/20/declassified-diplomacy-with-brazilnational-security-archive-hails-obama-administration-decision-to-assist-braziliantruth-commission/. Acesso em: mar. 2016.

CALLONI, Stella. Operación Condor: los años del lobo. Buenos Aires: Peña Lillo, 1999.

CARLSON, Peter. The Security Archive, Spilling government secrets. Washington Post. 8 mai. 2008, p. C4. Disponível em:

http://nsarchive.gwu.edu/nsa/Washington\%20Post\%202008\%20\%20Archive\%20profile.pdf. Acesso em maio 2016.

DINGUES, John. Os anos do Condor. Uma década de terrorismo internacional no Cone Sul. São Paulo: Companhia das Letras, 2004.

Documentos da NSA apontam Dilma Roussef como alvo de espionagem. G1. 1 set. 2013. Disponível em: http://g1.globo.com/politica/noticia/2013/09/documentos-dansa-apontam-dilma-rousseff-como-alvo-de-espionagem.html. Acesso em: mar. 2016.

ECKEL, Jan; MOYN, Samuel (Eds.). The breakthrough. Human rights in the 1970's. Pennsylvania: University of Pennsylvania Press, 2014.

FERNANDES, Florestan. Da guerrilha ao socialismo: a Revolução Cubana. São Paulo: T. A. Queiroz, 1979.

FICO, Carlos. O grande irmão: da Operação Brother Sam aos anos de chumbo. Rio de Janeiro: Civilização Brasileira, 2008.

\section{GANPHLAC}

Revista Eletrônica da ANPHLAC, ISSN 1679-1061, №. 25, p. 275-302, Jul./Dez., 2018.

http://revista.anphlac.org.br 
GASPARI, Elio. A ditadura escancarada. São Paulo: Companhia das Letras, 2002.

KORNBLUH, Peter. Chile and the United States: U.S. Policy toward Democracy, Dictatorship, and Human Rights, 1970-1990. National Security Archive. Disponível em: http://proquest.libguides.com/dnsa/chile;

http://search.proquest.com/dnsa_cl?accountid=169885. Acesso em maio de 2016.

The Pinochet file: a declassified dossier on atrocity and accountability.

New York: New Press, 2013 (e-book).

KUNZ, Diane B. (Ed.). The diplomacy of the Crucial Decade. American Foreign relations during the 1960. New York: Columbia University, 1994.

LEOGRANDE, William M.; KORNBLUH, Peter. Back channel to Cuba. The hidden history of negotiations between Washington and Havana. North Carolina: North Carolina Press, 2015 (e-book).

LOWY, Michel. Marxismo na América Latina: uma antologia de 1909 aos dias atuais. São Paulo: Perseu Abramo. 2006.

McSHERRY, J. PATRICE. Predatory states. Operation Condor and covert war in Latin America. New York: Rowman \& Littlefield Publishers, 2005 (e-book).

NOVARO, Marcos. Cables secretos. Buenos Aires: Edhasa, 2011.

OSÓRIO, Carlos; COSTAR, Kathleen. National Security Archive, Electronic Briefing Book ${ }^{\circ}$ 133, Kissinger to the Argentine generals in 1976: "If there are things that have to be done, you should do them quickly". Disponível em:

http://nsarchive.gwu.edu/NSAEBB/NSAEBB133/index.htm. Acesso em maio 2016.

OSÓRIO, Carlos. Argentina, National Security Archive, 1975-1980: The Making of U.S. Human Rights Policy. National Security Archive. Disponível em:

http://proquest.libguides.com/dnsa/argentina; http://search.proquest.com/dnsa_ar/productfulldescdetail?accountid=169885. Acesso em maio 2016.

National Security Archive. Electronic Briefing Book no 545. Obama Brings 'Declassified Diplomacy' To Argentina. Disponível em: http://nsarchive.gwu.edu/NSAEBB/NSAEBB545-Obama-brings-declassifieddiplomacy-to-Argentina-on-40th-anniversary-of-coup/. Acesso em: mar. 2016.

National Security Archive. Electronic Briefing Book n ${ }^{0}$ 546. Obama declassification may yeld new facts on Argentine dirty war. Disponível em: http://nsarchive.gwu.edu/NSAEBB/NSAEBB546-Obama-declassification-holdspromise-of-new-evidence-on-Argentine-dirty-war/. Acesso em: maio 2016.

National Security Archive. Electronic Briefing Book $n^{\circ} 588$. Trump continues US desclassified diplomacy with Aergentina. Disponível em: https://nsarchive2.gwu.edu/NSAEBB/NSAEBB588-Trump-release-continues-USdeclassified-diplomacy-with-Argentina/. Acesso em: dez 2017.

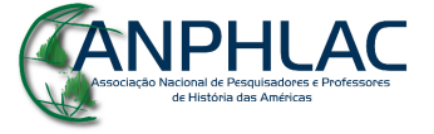

Revista Eletrônica da ANPHLAC, ISSN 1679-1061, №. 25, p. 275-302, Jul./Dez., 2018.

http://revista.anphlac.org.br 
ROUQUIÉ, Alain. O Extremo Ocidente: introdução à América Latina. São Paulo, Edusp, 1991.

SCHMIDLI, William Michael. The fate of freedom elsewhere. Human rights and U.S. Cold War policy toward Argentina. Ithaca: Cornell University Press, 2013.

SCHMITZ, David F. The United States and right-wing dictatorships. 1965-1989. Cambridge University Press, 2006.

SCHOULTZ, Lars. Estados Unidos: poder e submissão. Uma História da política norte-americana em relação a América Latina. Bauru: Edusc, 1998.

SANTOS, Marcelo. O poder norte-americano e a América Latina no pós-Guerra Fria. São Paulo: Annablume/Fapesp, 2007.

SIKKINK, Kathryn. Mixed signals. U.S. Human rights policy and Latin America. Ithaca: Cornell University Press, 2004.

TRACHTENBERG, Marc. The craft of international history. A guide to method. Princenton: Princenton University Press, 2006.

WEINSTEIN, Barbara. Pensando a história fora da nação: a historiografia da América Latina e o viés transnacional. A Revista Eletrônica da ANPHLAC, n. 14, p. 13-29, jan.-jun. 2013.

\section{GANPHLAC}

